\title{
Manual de las elecciones al Parlamento europeo
}

\author{
Antonio A. MARTINO*
}

El manual de elecciones europeas compilado por Donatella M. Viola contiene un marco teórico general y un modelo empírico común para analizar el comportamiento político del Parlamento europeo (PE) y las elecciones a éste, en los diferentes países, desde 1979. Contiene los elementos empíricos de las veintiocho monografías sobre cada uno de los países miembros y las conclusiones que tan monumental estudio comporta. Como tal, es un texto único y esencial. Es un libro que se ocupa de las elecciones del órgano de la Unión Europea que se elige por sufragio universal y directo por un periodo de cinco años.

En primer lugar, el interés en este volumen surge por la enorme cantidad de datos de las elecciones nacionales al pe y la claridad de la generalización de esos mismos datos en el marco teórico general y, en segundo, en las consecuencias que se obtienen de esta montaña de datos empíricos. Las dos partes teóricas pertenecen a la compiladora y anticipan las interrogantes que surgen hoy con los resultados del brexit y la serie de elecciones nacionales que se avecinan a lo largo del año en curso en Europa.

Cada vez la ciencia política tiende a producir manuales que describan el estado de la cuestión, porque puntualizar sobre una situación política requiere tiempo y esfuerzo. El texto que nos ocupa tiene la cualidad de estar destinado no sólo a expertos y operadores de la política, sino también a un público más amplio, por el cuidado en la elección de los términos y la generalidad de las descripciones. Dispone de análisis temporales cuantitativos y cualitativos. Es válido tanto para los politólogos (por sus análisis empíricos), como para los juristas, debido a sus descripciones

\footnotetext{
* Exprofesor de Ciencia Política, Pisa University, Italia (1976-2007). Profesor emérito de la Universidad Salvador, Argentina, <aamartino@gmail.com>.
} 
El texto permite

estudiar esas variables en cada uno de los sistemas políticos que analiza y sus repercusiones en el sistema total que es la Unión Europea. normativas y, en general, para todos los estudiosos de fenómenos sociales como son las elecciones.

Sin enunciarla, desarrolla una técnica sistémica: primero da el marco teórico que describe el sistema de Europa; luego, al analizar los subsistemas nacionales con sus núcleos y sus contextos, va mostrando cómo la estructura nacional se vincula con la supranacional, dándole entradas y recibiendo salidas; es decir, hay una composición de partes (la nacional) y un entorno (supranacional) que se presenta como entorno de los nacionales y que tiene con ellos intercambios y retroalimentación.

El mecanismo es el proceso de todo el sistema, por medio del cual se generan los cambios, la emergencia, la estabilidad, quizá el malestar y la propia destrucción del sistema. El texto permite estudiar esas variables en cada uno de los sistemas políticos que analiza y sus repercusiones en el sistema total que es la Unión Europea.

La introducción está a cargo de Joseph H.H. Weiler, quien destaca la oportunidad del texto en una época de descuido o interés superficial de un tema de tanta trascendencia política, y, en lo referente a la Introducción de Donatella M. Viola (en la que, entre otras cosas, cuenta las peripecias de su padre), aparece con toda claridad la necesidad de una Europa sin guerras ni violencias.

Hay un particular interés de este libro en Norteamérica. De hecho, la región está constituida por tres países: Canadá, Estados Unidos y México. Canadá se encuentra particularmente interesada en Europa por su doble filiación anglofrancesa. México, con los avatares que le procura la era de Donald Trump, se muestra muy interesado en la negociación que los otros dos grandes del Sur (Argentina y Brasil) están llevando con la Unión Europea para un pacto de preferencia y durabilidad. En tanto que en Estados Unidos hay mucha atención en la experiencia del PE, sobre todo desde el punto de vista de sus politólogos, particularmente los neofuncionalistas, que se inspiran en Karl W. Deutsch y Ernst B. Haas.

Podría decirse que hay más politólogos norteamericanos que europeos trabajando en el tema, debido a las particulares condiciones de enseñanza de la ciencia política en los seis principales países de la Unión Europea.

No puede perderse de vista que la experiencia de las elecciones directas del Parlamento europeo es sólo inferior en número al Parlamento indio y, por mucho, la experiencia más interesante de democracia representativa.

En Viola prevalece un espíritu indómito que le permite abarcar una obra extremadamente vasta, sin detenerse ante las dificultades que pre- 
senta; parece ser la prolongación del espíritu paterno -como lo indica ella misma-, quien debió afrontar riesgos enormes hacia el final de la segunda guerra mundial para llegar desde Bizt, Alemania, hasta el patrio Reggio Calabria, en Italia.

El volumen abre con tres capítulos de Donatella M. Viola sobre 1) la génesis del Parlamento europeo, a partir de la Asamblea Consultiva designada, hasta el Cuerpo Legislativo elegido directamente; 2) la composición interna y organización del pe y 3) teorías elecciones al Parlamento europeo: Second-Order Election y Europe Salience. Esta primera parte es un marco de referencia general, con los rasgos esenciales que luego caracterizarán los desarrollos de los capítulos siguientes, destinados a analizar cada uno de los casos nacionales de participación en la Unión Europea, empezando por los países fundadores y terminando por los recién llegados. Estos rasgos teóricos son de enorme importancia para la labor empírica realizada en la segunda parte, así como para obtener las conclusiones del final.

El modelo teórico único permite la comparación de datos y metodologías, pues de cada país hay tanto un perfil geopolítico, como una descripción de la política nacional, de los partidos políticos y su visión de la UE, la opinión pública, los sistemas electorales, detalles sobre los ejecutivos y las elecciones nacionales. Esto se repite en cada capítulo con la caracterización que cada autor brinda, pero respetando la visión comparatista que luego permiten los resúmenes de fondo.

En la segunda parte, en efecto, se analizan con métodos bien afirmados en la ciencia política, las características de los países que conforman la Unión Europea por parte de estudiosos nativos. La parte dedicada a Italia está a cargo de la propia compiladora.

En estos capítulos se brindan muchos datos nacionales, como elecciones, participación, perfiles de los eurodiputados electos, además de que permite comparar las elecciones europeas en cada país: dónde son obligatorias y dónde no, y ver los funcionamientos de los partidos nacionales, que luego tienen relevancia sobre las elecciones europeas.

Cabe recordar que el PE tiene partidos europeos que recogen, aglomeran o integran partidos políticos nacionales. En la actualidad, el Grupo del Partido Popular Europeo es el que más fuerza tiene (con 217 escaños), seguido del Grupo de la Alianza Progresista de Socialistas y Demócratas (con 188 escaños) y el Grupo de los Conservadores y Reformistas Europeos (con 74 representantes) y Grupo de Alianza Demócrata y Liberales (68 miembros del PE), Confederal de la Izquierda Unitaria Europea/Iz-
El modelo teórico único permite la comparación de datos y metodologías, pues de cada país hay tanto un perfil geopolítico, como una descripción de la política nacional, de los partidos políticos y de su visión de la Unión Europea. 
Este Manual [...] muestra claramente

la diversidad

de enfoques nacionales sobre

el papel y la manera de conformar (con elecciones) el

Parlamento europeo. quierda Verde Nórdica (52 curules). El grupo de los Verdes/Alianza Libre Europea tiene 51 escaños. Grupo Europa de la Libertad y de la Democracia Directa 42; Grupo Europa de las Naciones y de las Libertades 40 escaños (no inscritos 18). En total, 751 diputados, para formar un grupo se requieren al menos 40 .

Las comparaciones, que luego se resumen en cuadros muy ilustrativos, muestran cómo la participación en las elecciones europeas fue decayendo del 62 por ciento en 1979 hasta el 42 por ciento en 2014, con un espectacular 14 por ciento en las elecciones eslovacas.

De un modo relativamente simple, trata un tema sumamente complejo y de enorme vastedad, como es todo enfoque sistémico. Este Manual... muestra claramente la diversidad de enfoques nacionales sobre el papel y la manera de conformar (con elecciones) el Parlamento europeo. Estos modos nacionales de elegir no contribuyen en dar una unidad e igualdad a la condición de "europeos", pero es lo que existe y es bueno tener datos verdaderos (dicho esto en la era de la posverdad).

El punto relativo a las actitudes de los partidos nacionales respecto del favor o desconfianza con que ven a la Unión Europea es destacado y muy actual. El texto permite seguir la función de los grupos políticos en el PE y permite ver cómo la política exterior de cada país es recibida y actuada en el plano europeo.

Hoy más que nunca es necesario comprender y analizar el enorme mosaico de las realidades nacionales europeas, ya sea desde la organización jurídica de sus normas electorales, ya desde el complejo cuadro de la percepción política europea que cada Estado nacional ha forjado en el tiempo. Son veintiocho estados de larga tradición cultural y política, que no se agrupan fácilmente en un Estado supranacional, pero es interesante seguir el experimento.

A los vientos que permitieron pasar de un acuerdo sobre el carbón y el acero de pocos países, hasta lograr una compleja organización de los tres poderes en los veintiocho países europeos, desde la crisis de 2008, una nueva desconfianza acecha sobre Europa: la de quienes quieren salirse, pensando que de ese modo serán más fuertes. El brexit ha sido el golpe más duro, pues muchos partidos alimentan el espejismo de la grandeza nacional en soledad, una suerte de populismo nacional.

Las grandes dificultades que resquebrajan y ponen en tela de juicio el espíritu de la UE sólo pueden superarse a la luz de la cosmovisión que impulsó a los padres fundadores. La prioridad del Movimiento Fede- 
ralista Europeo no eran los bancos ni la moneda, sino la paz, junto a la gradual integración política y social. Los retos de la UE son políticos; se resuelven superando los nacionalismos estatales. Es una política de largo plazo contra las inquietantes políticas de sobrevivir el día a día.

Los duros y negativos resultados que ha cosechado Gran Bretaña, que aún no ha iniciado el camino del alejamiento de la Unión -sólo posible con la activación del artículo 50 del Tratado de Lisboa- hacen repensar el dicho de que "Europa mejora sólo con más Europa".

Hoy, a 43 años del ingreso del Reino Unido, no se ha tomado conciencia de lo que significa el brexit para la UE, incluso para los mismos ingleses: exacerbación de nacionalismos (potenciado por la crisis migratoria), efecto "arrastre" para otros países, que consideren no necesario un gobierno bajo el marco normativo comunitario, desplome del andamiaje institucional, funcionamiento del "sálvese quien pueda", el fin de las solidaridades comunitarias, enfrentamientos entre países, grave crisis económica, recesión e incertidumbre.

Parece que los ingleses se hubiesen autolesionado con el brexit: caída de la libra, peor calificación de Standard \& Poor's, fuga de las empresas, fuga de los bancos de Londres, amenaza de secesión de Escocia, Gales y hasta Irlanda del Norte, falta de fondos para afrontar el gasto publico. Pero no mucho cambiará para Europa, pues Gran Bretaña no participaba en la moneda común, ni en la Carta de los Derechos Fundamentales ni de la justicia común tampoco de los negocios internos; era parcial en aplicar el Acuerdo Schengen y, en esencia, participaba en el mercado único como Noruega y Suiza, que están fuera de la UE, pero están obligados a respetar las normas y contribuir al balance europeo. El tiempo lo dirá. La amenaza de la secesión de Escocia amenaza un nuevo referéndum.

El complejo funcionamiento de los tres poderes, la enorme dificultad de seguir los vericuetos de la legislación y la necesidad de dar respuestas federales a países de tradición unitaria, dificultan -a los ojos del desprevenido ciudadano- la visión de la pujanza de una Europa unida, por ello es importante revisar los datos que implacablemente se van acumulando sobre las realidades nacionales, para dibujar un complicado pero entusiasta cuadro que ya se intenta imitar en otras latitudes, como el Parlasur y el Parlamento centroamericano.

Este Manual... permite evaluar resultados, no siempre halagüeños, pero sí científicos. La ventaja de una ciencia social numeral, introducida por la estadística hace muchos años, aquí se puede tocar con la mano.
Los retos de la Unión Europea son políticos; se resuelven superando los nacionalismos estatales. Es una política de largo plazo contra las inquietantes políticas de sobrevivir el día a día. 
Este libro muestra

-sin tanto énfasis

en la calidad democrática de las elecciones y sus sistemas de votosy pone de relieve los ideales de los creadores de la Unión Europea: paz, democracia y solidaridad.
La fuerza del marco teórico permite siempre seguir las importantes descripciones nacionales, las cuales difieren por ser locales y lograr una síntesis parcial y final en los capítulos indicados.

El método es severo y no se detiene ante datos nefastos, como los referentes a la abstención, sobre todo en 2014. Se trata de una obra científica y no partisana; por lo tanto, no hay tomas de posiciones, sino descripciones de hechos. Los problemas religiosos y de creencias se mezclan con las condiciones que las legislaciones nacionales destinan a las diferentes regiones, encontrándose algunas sobrerrepresentadas y otras casi ausentes, en términos de elección de legisladores europeos. Este tema es difícil de superar, al menos por ahora, y requerirá más atención en el futuro inmediato.

$\mathrm{El}$ análisis de los sistemas nacionales permite apreciar las diferencias entre eurodiputados, quienes tienen un anclaje en el territorio donde fueron electos, distinto del de aquellos que pertenecen a circunscripciones mastodónticas que alejan la posibilidad de tener a mano las necesidades y urgencias. Se distingue también entre los eurodiputados que provienen de sistemas políticos pro europeos, de quienes provienen de sistemas euroescépticos. Incluso dentro de los sistemas políticos nacionales hay partidos o grupos de estos que hoy juegan al eurocentrismo y los que quieren desvincularse en aras de una mayor independencia en un mundo siempre más complejo e interrelacionado.

Este libro muestra -sin tanto énfasis en la calidad democrática de las elecciones y sus sistemas de votos-y pone de relieve los ideales de los creadores de la UE: paz, democracia y solidaridad.

La parte más valiosa - para quien esto escribe- se encuentra en los dos capítulos finales, a cargo de Viola: el análisis comparativo de las elecciones europeas, en el que se retoman los puntos sugeridos en la primera parte, luego de los análisis individuales, y el Epílogo, con viejas y nuevas tendencias de las elecciones europeas de 2014, de gran actualidad en nuestros días.

En las conclusiones es evidente que ninguno de los esquemas interpretativos se considera definitivo. Hay problemas y dificultades en unos y otros, mas no se excluye la posibilidad de encontrar un modelo teórico unitario en un futuro próximo.

Tiene apéndices e índices de enorme utilidad en el complejo universo de los temas y países estudiados. En particular el cuadro 31.1 de los Estados miembros de las características clave (p. 676), y el cuadro 31.4b 
Partidos euroescépticos/eurocríticos en la vieja UE y países de la ampliación (p. 690).

Se muestra, como lo aclara Weiler en la Introducción, que el periodo de mayor poder del PE coincide con el de mayor desinterés por el papel fundamental que desarrolla a nivel de percepción política. Esto, obviamente, se relaciona también con temas coyunturales (como las crisis económicas y las xenófobas).

Este volumen termina con un Epílogo en el que se concentra la última elección (entre el 22 y el 25 de mayo de 2014) del PE en los veintiocho países de los Estados miembros.

Es una obra rigurosa, llena de datos empíricos y, por ende, ricos para el análisis y difíciles de caracterizar en pocos renglones. Muestra la realidad de una Europa sofisticada, con fallas a la hora de las obligaciones comunes, pero siempre un punto de referencia para los países que la conforman, así como ejemplo para toda la comunidad internacional de un experimento de convivencia multicultural, multirracial, multirreligiosa y multicreencias, pero consciente de un destino de grandeza y consideración que ninguno de los estados nacionales ha logrado en un ámbito de convivencia hacia la paz organizada. Podría decirse que la UE tiene propiedades emergentistas (propias del todo), que ninguna de las partes separadas puede conseguir motu proprio.

\section{FuENTES}

\section{Analizadas}

Viola, Donatella M., comp.

2016 Routledge Handbook of European Elections, Londres, Routledge (Handbook), 786 pp.

\section{Consultadas}

Amato, Giuliano, Guy Braibant y Evangelos Venizelos, eds.

2002 Towards a European Constitution: The Role of the European Parliament in the Constitutional Review in Today's Europe, Londres, Esperia, pp. 629-651.
El periodo

de mayor poder del Parlamento Europeo coincide con el de mayor desinterés por el papel fundamental que desarrolla a nivel de percepción política. 
Hix, Simon y Michael Marsh

2007 "Punishment or Protest? Understanding European Parliament Elections", The Journal of Politics, vol. 69, no. 2, pp. 495-510.

Martino, Antonio A.

2013 "La sistémica en Mario Bunge (aproximación)", Pisa, Università di Pisa, 26 de abril, en <http:/ / es.slideshare.net/dmelop/lasistemica-en-mario-bunge $>$.

ReIF, Karlheinz y Hermann Schmitt

1980 "Nine Second-Order National Elections-A Conceptual Framework for the Analysis of European Election Results", European Journal of Political Research, vol. 8, no. 1, pp. 3-44. 